Sastoque, J. I. (2016). Método de estimación del valor de uso de activos utilizados en operaciones de subastas ganaderas con Montecarlo. Revista Lebret, 8. Bucaramanga, Colombia: Universidad Santo Tomás. pp. 25 - 55. ISSN: 2145-5996

\title{
Método de estimación del valor de uso de activos utilizados en operaciones de subastas ganaderas con Montecarlo*
}

\section{Methods to calculate the value-in-use of assets used in cattle sales using Montecarlo}

José Isnardi Sastoque Rubio ${ }^{l}$

\begin{abstract}
Resumen
Basado en un análisis teórico de los métodos de valoración de activos generalmente aceptados y los modelos avanzados que se han estructurado como el de rentas actualizadas cuya metodología de aplicación se asemeja al valor de uso determinado por la Norma Internacional de Contabilidad (NIC 36) para definir uno de los importes recuperables, en este documento se expone la aplicación del citado modelo sometido a analisis de escenarios a través del método Montecarlo, utilizando como información de base, las inversiones en terrenos y corrales y los flujos de caja operacionales que puede generar las empresas de subastas ganaderas del departamento del Meta, a partir de un caso particular, para lo cual se tienen en cuenta los eventos aleatorios que puede generar el mercado, los cuales son representados por los sistemas de distribución de las variables determinantes, pretendiendo contrastar el resultado con el valor en libros contables, para identificar un posible deterioro.
\end{abstract}

\section{Palabras clave}

Rentas actualizadas, valoración, flujo de caja, Montecarlo.

\section{Códigos de clasificación JEL: M4, M41}

\begin{abstract}
Based on a theoric analysis of the assessment methods of generally accepted assets and the advanced models which have been structured, like the updated rent to who's application methodology assimilate the predetermined use of the International Accounting Standard (IAS 36) to define one of the important recoverebles, In this document, the application of the cited model under staged analysis through the Monte Carlo method are exposed. Utilizing as base information the investments made on terrain, corrals, and the flow made by operational registers that the auction companies in the Meta department can make starting at a particular case, for which random events generated by the market are taken into account and represented by the distribution system of the predertermined variables. A contrast of the result with the value on the accounting books is used to identify a possible deterioration.
\end{abstract}

\section{Keywords}

Updated rent, assessment, cash flow, Montecarlo.

* Artículo derivado del proyecto de investigación: "Análisis del deterioro de la propiedad planta y equipo utilizada en las operaciones de subasta y feria del sector ganadero del departamento del Meta de acuerdo con la NIC 36" Financiado por la Dirección General de Investigaciones de la Universidad de los Llanos.

1 Magíster en Finanzas. Docente Universidad de los Llanos, Facultad de Ciencias Económicas. Vinculado al grupo de investigación TRIFIN. Correo electrónico: jisastoque@unillanos.edu.co 


\section{Introducción}

La aplicación de la NIC 36 en Colombia plantea a las empresas, sin distingos de sector o actividad económica, un compromiso de presentar al final de cada período la información financiera de los activos, el fondo de comercio y los intangibles, cuyo valor en libros no se encuentre por encima de su importe recuperable, ya que, de darse este caso, se podría registrar un deterioro afectando los resultados del período.

Inicialmente en este estudio, se abordan los métodos de valoración de activos haciendo énfasis en las distintas teorías sobre el concepto de valor que fueron la génesis para el surgimiento de técnicas sofisticadas que permiten valorar los activos de forma individual o integrada a través de unidades generadoras. Los métodos de valoración generalmente aceptados fueron consolidándose a través de la inclusión de técnicas comparativas para luego dar paso a métodos avanzados de valoración que incluyen precios hedónicos, inteligencia artificial, análisis espacial y modelos autoregresivos integrados de medias móviles (ARIMA).

La metodología de valoración establecida en Colombia comprende el método comparativo o de mercado, de capitalización de rentas o ingresos y el de técnica residual.

Seguidamente, la investigación aborda la pérdida de valor a través del concepto de depreciación para aquellos activos independientes del suelo y los terrenos mediante la observación de métodos que se correlacionan con su vida útil y con el uso.

Para finalizar, mediante la aplicación del software Risk Simulator y el método Montecarlo se realiza una valoración parcial a través del método de rentas actualizadas de los terrenos y corrales de un centro de feria ganadera donde se realizan subastas, ubicado en el municipio de Puerto López, Meta, partiendo de los ingresos obtenidos por el volumen de transacciones y el porcentaje de comisión de los operadores en el 2014. Seguidamente se estima la distribución de probabilidad, utilizando el estadístico Kolmogorov - Smirnof y unos supuestos para egresos para obtener el flujo de caja del período en un horizonte de 10 años y descontarlo con un referente de buen desempeño en el mercado bursátil, para ello se toma la tasa de rendimiento de una de las acciones del mercado de valores colombiano durante el año 2014, teniendo en cuenta que el benchmark COL20 de la Bolsa de Valores de Colombia no tuvo buen comportamiento en los períodos 2014 y 2015.

\section{Análisis teórico de los métodos de valoración de activos fijos}

El concepto de valor enmarca el punto de partida en el objeto de análisis de este artículo, por tanto, su comprensión conceptual es de gran importancia. Su definición tiende a ser confusa, para algunos autores como Bunge (1985), por la dificultad de su mensurabilidad, desde la misma percepción Ricardiana y su concepción objetiva 
(valor de uso), en la que no se difiere si su determinación depende de necesidad o de su escasez; o la concepción de Marx que lo define como el trabajo socialmente necesario, en defensa de la plusvalía.

Carl Menger (VV. AA., 2009) proporciona una definición más clara respecto al concepto de valor, al indicar que todos los bienes en que se haya la relación cuantitativa descrita, la satisfacción de una determinada necesidad humana, depende, pues, de que se disponga o no de una cantidad concreta y prácticamente significativa de aquellos bienes. Si los sujetos económicos adquieren conciencia de esta situación, entonces tales bienes adquieren para ellos aquella significación que llamamos valor. Por tanto, este fenómeno vital que llamamos valor de los bienes brota de la misma fuente que el carácter económico de estos últimos, es decir, entre la necesidad y masa de bienes disponible, en este orden de ideas obedece a la oferta y demanda.

Jara, Torres y Contreras (2009) proponen una modelación general para la aplicación de la NIC 36 en sociedades anónimas abiertas con baja presencia bursátil en Chile, los autores enfatizan la obligación por parte de las empresas de desarrollar modelos para determinar un posible deterioro de sus activos al aplicar las disposiciones de la NIC 36. Sus conclusiones hacen referencia a los múltiples factores que dificultan la utilización de la norma, debiendo cada empresa según su actividad preparar su propio modelo.

A nivel nacional, Perea (2014) aborda el deterioro de los activos señalado en la NIC 36 desde la óptica de autores clásicos y neoclásicos de la economía y profundiza en el análisis de los conceptos vinculados al deterioro de valor los cuales son los valores razonables y de uso. Sus conclusiones se basan en el que el valor razonable menos los costos de venta o el valor de uso representan una forma de valoración más fiable de los activos de la empresa para identificar un posible deterioro.

Para efectos de asignación de precios a estos bienes, en particular los activos tangibles, que es el objeto central de este análisis, se han agrupado en cuatro categorías en general, representadas por: propiedad personal, inmuebles, maquinarias y equipos y bienes agropecuarios (KPMG, 2014).

\section{Métodos de valoración generalmente aceptados}

De acuerdo con Guadalajara (2014, citado en Rey, 2014), los orígenes epistemológicos de los métodos de valoración se remontan al año 3000 a. C. En Egipto, frente a la necesidad de valorar la tierra, en este sentido los orígenes de la valoración se han centrado en la tasación inmobiliaria, cuyo desarrollo teórico es relativamente reciente de acuerdo con Bernat (2010, citado en Rey, 214), surgiendo las primeras obras en la segunda mitad del siglo XIX.

Según González, Turmo de Padura y Villalonga (2006), en general los métodos de valoración aplicables a cualquier tipo de bien se pueden clasificar en dos grandes 
grupos, representados por técnicas comparativas y métodos basados en técnicas analísticas.

Las conceptualizaciones realizadas por González, et al. (2006) se orientan en términos de la valorización de inmuebles como edificios y terrenos, por lo cual las definiciones que se describen a continuación se extienden a todos los activos tangibles que se requieren tener en cuenta para efectos de determinación de valor.

Ampliando la propuesta de González, et al. (2006), la técnica comparativa consiste en comparar el activo objeto de la tasación con otro de semejantes cualidades o características de los que se conoce su precio, los cuales se toman como referentes a partir del mercado correspondiente al activo obteniendo así el valor de mercado del bien a valorar.

Las comparaciones deben realizarse con base en uno o varios signos externos, también llamados variables exógenas o explicativas.

El método de la técnica comparativa a su vez se subdivide en método sintético, método de análisis de regresión simple o múltiple y el método Beta.

El método síntesis consiste en realizar comparaciones del activo sujeto a valoración con otros de similares características, tratando de obtener el mayor número de referentes posibles, que corresponda al mismo contexto geográfico, o en zonas geográficas diferentes, pero con características económicas homogéneas y que su destinación tenga el mismo uso funcional, conociendo su precio de oferta o de transacción real que se conozca, fundamentándose así la metodología en el principio de sustitución.

El método de análisis de regresión simple o múltiple parte del supuesto que al poder desarrollarse el método de síntesis, a partir de variables explicativas comunes a los activos que se comparan, entonces la determinación del valor puede someterse a estimación a través de la aplicación de métodos de regresión donde la variable dependiente representada por el valor de mercado por estimar, estará en función de una o más variables explicativas con un alto nivel de confianza en la predicción, como se expresa en la ecuación 1.

$$
\text { (Ecuación 1) } \hat{Y}=f\left(X_{1} ; X_{2} ; X_{3} \ldots X_{i}\right)
$$

Donde $\hat{Y}$, representa el precio estimado, y las variables $X_{1}, X_{2} \ldots X_{i}$, representan las variables explicativas o determinantes del valor del precio del activo a valorar.

De esta manera, se espera estimar una ecuación lineal que refleje el comportamiento del precio con un alto nivel predictivo, con la estructura funcional que se representa en la ecuación 2.

$$
\begin{gathered}
\left(\text { Ecuación 2) } \hat{Y}=\alpha+\beta_{1} X_{1}+e(\text { Regresión Simple })\right. \\
\hat{Y}=\alpha+\beta_{1} X_{1}+\beta_{2} X_{2}+\ldots \beta_{i} X_{i}+e(\text { Regresión Múltiple })
\end{gathered}
$$


Donde los $\beta_{-}$i representan los coeficientes de correlación que expresan la capacidad de generar valor al activo la variable explicativa, el intercepto $\alpha$, representa el valor que no puede ser explicado por las variables regresoras y la variable aleatoria "e" representa el efecto de las variables endógenas en el modelo, el cual, se asume, tiende a cero, por lo que se omite del modelo predictivo.

Vale aclarar que la aplicabilidad y fiabilidad de estos modelos dependerá de la disponibilidad de información estadística suficiente respecto a las variables por tener en cuenta para cada tipo de activo.

El método beta, por su parte, fue propuesto por primera vez por Ballestero, al que se le han realizado ajuste a través de estudios posteriores que han perfeccionado esta técnica, la cual consiste en comparar dos sistemas de distribución que pueden ser del tipo triangular o rectangular, que de acuerdo con González, et al. (2006), su aplicación es poco usual en la valoración inmobiliaria urbana, pero sí es aplicable en la valoración de inmuebles de la valoración agraria y se puede hacer extensiva a la valoración de maquinarias, equipos, en mobiliarios de lujo y obras de arte, en especial a través del uso de métodos tales como Montecarlo, en los diversos software que permiten su aplicación.

La segunda categoría de los métodos de valoración, tomando como base los planteamientos de González, et al. (2006), correspondiente a técnicas analísticas, se centran en el uso de modelos matemáticos con un grado de sofisticación, los cuales pueden ser utilizados para estimar el costo de activos inmobiliarios como edificios y para estimar el valor de mercados de muebles e inmuebles, partiendo de ciertos datos o hipótesis económicas, dentro de esta metodología se encuentran el Método de costo de remplazamiento o reposición, Método del valor residual estático y dinámico, Método de actualización de rentas y Métodos homologados.

El método de remplazamiento de acuerdo con González, et al. (2006) consiste en determinar el costo total de remplazar el bien en negociación por otro con iguales características y nivel tecnológico, en aspectos tales como, capacidad, uso, calidad, estado o conservación, entre otras.

Siguiendo a González, et al. (2006) este método se fundamenta en el principio de valor residual y permite calcular el costo de todos los muebles e inmuebles de forma separada o conjunta. Adaptando de manera generalizada la fórmula a todo tipo de activo tangible, que pueda convertirse en una unidad generadora de efectivo, se tiene la siguiente fórmula.

$$
\text { (Ecuación 3) } V R B=F+C_{C}+I_{N}+H+L+T+G_{P}^{A}
$$

Dónde:

$V R B$ : Valor de remplazo bruto o nuevo

$F$ : Valor de mercado del bien 
$I_{N}$ : Impuestos no recuperables del orden nacional y aranceles necesarios para la adquisición del bien

$H$ : Honorarios por consultoría y asistencia técnica

$L+T$ : Costo de licencias y trámites asociados del proceso

$G_{P}^{A}$ : Gastos administrativos del promotor

Todas las variables deben ser consideradas a fecha de valoración.

(Ecuación 4) $V_{m}=F+C_{C}+I_{N}+H+L+T+G_{P}^{A}+G_{F}+G_{C}+B_{P}$

Las variables adicionales no representan o consideran como gastos necesarios.

Dónde:

$\mathrm{V}_{\mathrm{m}}$ : Valor de mercado

$\mathrm{G}_{\mathrm{F}}$ : Gastos financieros incurridos

$\mathrm{G}_{\mathrm{C}}$ : Gastos de comercialización de las unidades funcionales que componen el activo.

Siguiendo con la explicación de los métodos de la Técnica analítica, el método del valor residual estático y dinámico consiste en determinar el valor de mercado del activo para su rehabilitación, a partir de las adecuaciones o reparaciones necesarias para su puesta en marcha, deduciendo de todos los gastos e inversiones necesarias para tal fin, incluyendo los gastos financieros, comerciales y beneficios presumibles que un inversor promedio esperaría.

Las aplicaciones del método tienen dos subdivisiones, el residual dinámico y el estático, a continuación se abordan por separado los respectivos métodos.

El método residual dinámico o análisis de inversiones con valores esperados, implica realizar el cálculo, teniendo en cuenta el proceso de puesta en marcha o rehabilitación del activo, hasta generar el proceso de realización en el mercado del bien final y generando cada uno de los ingresos, egresos e inversiones de cada período causado y descontando los flujos de caja esperados a la tasa de descuento del mercado, en ese momento, para ese producto y esa región que un inversionista promedio tenga mayor probabilidad de realizar.

Matemáticamente, quedaría expresado:

Dónde:

$$
\text { (Ecuación 5) } f=\sum \frac{\text { Fin }_{j}}{(1+i)^{t j}}-\sum \frac{F e_{k}}{(1+i)^{t k}}
$$

$f$ : Valor actual del activo a rehabilitar

Fin $_{j}$ : Flujo de ingresos generado en cada momento $j$ 
Fek: Flujo de egresos para cada momento k

$t j$ : Período previsto entre el proceso de negociación hasta que se produce cada ingreso.

tj: Período previsto entre el proceso de negociación hasta que se produce cada egreso.

$i$ : Tasa de oportunidad elegida para el período previsto

El método residual estático ofrece una técnica más sencilla que subsana la dificultad de obtener algunos de los datos que demanda el método dinámico, el cual se realiza sin tener en cuenta el factor tiempo, pero si todos los componentes que inciden en el valor.

$$
\text { (Ecuación 6) } f=V_{m} *(1-b)-\sum C_{i}
$$

Dónde:

$f$ : Valor del activo por rehabilitar

$V_{m}$ : Valor del activo rehabilitado

$b$ : Porcentaje de beneficio esperado por el inversor

$C_{i}$ : Cada uno de los costos y gastos necesarios considerados

El cuarto método asociado a la técnica analítica, representado por el método de actualización de rentas, que al igual que los anteriores métodos se encuentra asociado a las valoraciones inmobiliarias, pero que es aplicable para activos fijos como maquinarias, equipos y otros, al determinar el valor del bien a partir de las rentas futuras esperadas de todas las rentas futuras asociadas al activo, para lo cual se requiere como mínimo seis datos de rentas comparables que reflejen la situación real de este mercado y contar con información suficiente sobre transacciones de oferta del bien que permitan identificar los parámetros adecuados para realizar la homogenización de rentas comparables, registro de información contable de la unidad generadora y requisitos legales asociados.

De acuerdo con lo anterior, el valor atribuible al bien, dependerá de la renta que produce o puede producir en el desarrollo de una actividad económica, por lo cual su conceptualización se puede sintetizar como la determinación del precio que un empresario promedio estará dispuesto a pagar por la adquisición del activo en función de las expectativas de retornos esperados de este. La fórmula de estimación se muestra a continuación.

Dónde:

$$
\text { (Ecuación 7) } f=\sum \frac{F i n_{j}}{(1+i)^{t j}}-\sum \frac{F e_{k}}{(1+i)^{t k}}+\sum \frac{V_{r e}}{(1+i)^{n}}
$$

$F$ : Valor actual neto del activo 
Fin $_{j}$ : Flujo de ingresos generado en cada momento $j$

$\mathrm{Fe}_{k}$ : Flujo de egresos para cada momento $k$

$V_{r e}:$ Valor del activo al término en el período de culminación de su vida útil $\mathrm{n}$, (denominado valor de reversión)

$t j$ : Período previsto entre el proceso de negociación hasta que se produce cada ingreso

tk: Período previsto entre el proceso de negociación hasta que se produce cada egreso

$i$ : Tasa de oportunidad elegida para el período previsto

$n$ : Numero de períodos de tiempo desde la negociación hasta el final del período estimado de los ingresos esperados.

Para su estimación el valorador o tasador deberá justificar y exponer en su informe las hipótesis y parámetros de cálculos utilizados.

Los métodos homologados que representan el quinto y último método de la técnica analítica, se desarrolla a través de un proceso comparativo que requiere de un estudio de mercado, a partir de un proceso de muestreo, por medio del cual se obtienen las muestras comparables, definiendo previamente las características que se deben tener en cuenta desde una escala de valores cualitativos y los factores aplicables para cada característica, para posteriormente definir un promedio a partir de los coeficientes aplicables a cada muestra y su valor estimado o testigo.

De acuerdo con esta definición se puede definir el valor estimado promedio de los homólogos, mediante la siguiente fórmula de estimación:

$$
\text { (Ecuación 8) } \bar{f}=\frac{\sum_{\substack{i=1 \\ j=1}}^{n} C_{j} * V_{H_{i}}}{n}
$$

Dónde:

$\bar{f}$ : Valor promedio de los activos homologados a través del estudio de mercado

$C_{j}$ : Coeficiente técnico definido para cada característica $\mathrm{j}$, a partir de una escala cualitativa, dada la escala de valor correspondiente (se espera que )

$V_{H i}$ : Valor de mercado homogeneizado para el activo o muestra $\mathrm{i}$

$i$ : Observaciones que toman valor de 1 a n muestras

$j$ : Número de características definidas para realizar el proceso de que toman valores de 1 a $m$ características a valorar. 
$n$ : Número total de muestra definida técnicamente a través de procesos de muestreo comprobado.

La aplicación de este método se fundamenta en diez principios, bajo los que se basa la legitimidad del procedimiento a saber: 1. principio de anticipación, 2. Principio de finalidad, 3. principio de mayor y mejor uso, 4. Principio de probabilidad, 5. Principio de proporcionalidad, 6. Principio de prudencia, 7. Principio de sustitución, 8. Principio de temporalidad, 9. Principio de transparencia y 10. Principio de valor residual. Estos principios se describen en el apéndice A.

\section{Métodos avanzados de valoración}

De acuerdo con Gallego (2008, citado en Rey, 2014), estos métodos se caracterizan por el uso de técnicas matemáticas para la estimación del valor, mediante un procedimiento sistemático que las reviste de un carácter más científico, generando resultados más objetivos.

La denominación de métodos, como avanzados, según Rey (2014), obedece a la categorización de algunos autores, tales como Pagourtzi (2003), Selim (2009) y Kusan, Aytekin y Özdemir (2010).

Siguiendo a Rey (2014), estos métodos tienen como valor agregado el generar una mayor producción de valores que las tradicionales, ya que permite realizar valoraciones masivas. Los cuales están representados con precios hedónicos, Inteligencia artificial, Análisis espacial, K-Vecino, Métodos basados en teorías de decisión multicriterio, Modelos auto regresivos integrados de medias móviles (ARIMA). A continuación, se pretende dar una descripción general de estos métodos

El método de Precios hedónicos, de acuerdo con Rey (2014), consiste en determinar cuáles son los atributos de un bien que explican su precio y conocer la valoración ponderada que se otorga a cada uno de ellos. Este método fue difundido por las investigaciones adelantadas por Griliches (1971) y Rosen (1974) (citados en Rey, 2014), quienes proponen las bases teóricas del equilibrio de mercado, tanto desde el punto de vista del consumidor como del productor, dando paso a la aplicación de la econometría para la determinación de los precios hedónicos.

El método de redes neuronales artificiales (RNA), de acuerdo con Rey (2014), está conectado con el campo de la inteligencia artificial (IA), el cual según Martin y Sanz (citados en Rey, 2014), se definen como un conjunto de algoritmos cuyo fin es estimar el razonamiento humano a través de una lógica deductiva o manipulación de símbolos.

Por otra parte, respecto a la valoración de activos tangibles se aplica el método perceptron multicapa-Multi Layer Perceptron(MLP), el método Base Radial-Radial Basis Funtion (RBF) y los mapas Auto-organizados de Kohonen-Self-Organization Maps (SON), de acuerdo con lo citado por Rey (2014) respecto de García Rubio 
(2004); Kauko (2009); y Kontrina y Verika, (2009), que permiten establecer el valor a reportar técnicamente en los estados financieros respecto a valor de marca y buen nombre.

El método Análisis espacial, de acuerdo con Rey (2014), parte del supuesto de que la localización geográfica afecta la demanda de activos inmobiliarios por diversas variables, que no solo se limita a aspectos tales como el costo de transporte y acceso, sino que se extienden a variables derivadas de las externalidades de tipo ambiental, calidad de equipamiento, niveles de seguridad, entre otros. Este método se apoyó en la tecnología que brindan los sistemas de información geográficos, generando mapas de precios que permitan contemplar la evolución espacial de estos, a través de la cual se puede definir una función que permita predecir el precio de un bien inmobiliario.

El método K-Vecino, de acuerdo con Gallego (citado en Rey, 2014), este método consiste en la utilización de un algoritmo KNN, que no parte de la aplicación de una fórmula de estimación, sino que se fundamenta la estimación la cual se realiza a partir de bienes inmuebles que tienen mayor similitud o vecinos más próximos, acorde con los criterios de comparación definidos en el algoritmo.

El cuarto método avanzado, según la descripción de Rey (2014), está representado por la teoría de decisión multicriterios, el cual puede ser aplicado a diversos tipos de valoración, teniendo en cuenta aspectos intangibles del bien a valorar, para su aplicación se requiere normalizar la información antes de ser aplicado, para facilitar el proceso de comparabilidad en relación con las unidades de medidas.

Los modelos autorregresivos integrados de medias móviles (ARIMA), por su parte, son aplicaciones econométricas que permiten resolver problemas asociados a series no estacionarias, por efectos de una tendencia. De acuerdo con los análisis de Rey (2014), respecto a los aportes de Box y Jenkins, los resalta en el desarrollo de un cuerpo metodológico destinado a identificar, estimar y diagnosticar modelos dinámicos de series temporales en los que la variable tiempo resulta ser fundamental.

La aplicación del modelo ARIMA se ha hecho extensiva a la valoración, en especial de bienes inmobiliarios, tal como resalta Rey (2014), respecto al trabajo de Tse (1997) quien estimó la valoración para propiedades inmobiliarias en Hong Kong.

\section{Métodos de valoración de activos tangibles aplicados por firmas valuadoras}

Las firmas que prestan servicios de valoración, para fines de practicidad, tienden a centrar en máximo cuatro métodos, que obedecen en esencia a los métodos generalmente aceptados, con un grado menor de complejidad en su aplicación, para el caso de firmas como Cutting Through Complexity (KPMG) de México, la valoración de los activos tangibles representados por propiedad personal, maquinaria y equipos, inmuebles y bienes agropecuarios debe realizarse teniendo en cuenta la realidad de cada negocio, utilizando el método que más se adapte a cada necesidad. Esta firma 
propone tres métodos representados por el enfoque de ingreso, enfoque de mercado y enfoque de costo.

El enfoque de ingreso se aplica determinando el valor de los activos tangibles, a través de la estimación de las principales variables relativas a la renta de estos; el enfoque de mercado, por su parte, se estima mediante comparaciones de ventas de mercado reciente $u$ oferta de activos equiparables en este sentido correspondería al método de síntesis antes mencionado; mientras que en el método del costo la estimación se realiza en base a la vida útil del activo remanente, estado de conservación y grado de obsolescencia.

Frente a las diversas metodologías disponibles desde el punto de vista científico, académico y técnico los valuadores cuentan con suficientes herramientas para garantizar informes objetivos para los fines que se requiera.

\section{Métodos de valoración establecidos a nivel normativo en Colombia}

La normatividad en Colombia definida respecto a los avalúos se centra en los definidos a nivel catastral, siendo la autoridad al respecto el Instituto Geográfico Agustín Codazzi (IGAC), el cual define como aplicables el comparativo o de mercado, de capitalización de rentas o ingresos y técnica residual.

\section{Método comparativo o de mercado}

De acuerdo con el artículo $1^{\circ}$ de la Resolución 620 de 2008, es una técnica valuatoria que busca establecer el valor comercial del bien, a partir del estudio de las ofertas o transacciones recientes, de bienes semejantes y comparables al del objeto de avalúo. Tales ofertas o transacciones deberán ser clasificadas, analizadas e interpretadas para llegar a la estimación del valor comercial.

\section{Método de capitalización de rentas o ingresos}

La Resolución 620 de 2008 del Instituto Geográfico Agustín Codazzi en el artículo 2, al respecto del método de capitalización de rentas e ingresos expresa:

Es la técnica valuatoria que busca establecer el valor comercial de un bien, a partir de las rentas o ingresos que se puedan obtener del mismo bien, o inmuebles semejantes y comparables por sus características físicas, de uso y ubicación, trayendo a valor presente la suma de los probables ingresos o rentas generadas en la vida remanente del bien objeto de avalúo, con una tasa de capitalización o interés.

Parágrafo. Se entiende por vida remanente la diferencia entre la vida útil del bien y la edad que efectivamente posea el bien. Para inmuebles cuyo sistema constructivo sea muros de carga, la vida útil será de 70 años; y para los que tengan estructura en concreto, metálica o mampostería estructural, la vida útil será de 100 años (Resolución 620 de 2008 del IGAC, art. 2, p. 2). 


\section{Método de costo de reposición}

La Resolución 620 de 2008 del Instituto Geográfico Agustín Codazzi en el artículo 3, al respecto del método de costo de reposición expresa:

Es el que busca establecer el valor comercial del bien objeto de avalúo a partir de estimar el costo total de la construcción a precios de hoy, un bien semejante al del objeto de avalúo, y restarle la depreciación acumulada. Al valor así obtenido se le debe adicionar el valor correspondiente al terreno. Para ello se utilizará la siguiente fórmula:

$$
\text { (Ecuación 9) } V_{C}=\{C t-D\}+V t
$$

Dónde:

$V c$ : Valor comercial

$C t$ : Costo total de la construcción

$D$ : Depreciación

$V t$ : Valor del terreno

Parágrafo. Depreciación. Es la porción de la vida útil que en términos económicos se debe descontar al inmueble por el tiempo de uso, toda vez que se debe avaluar la vida remanente del bien.

Existen varios sistemas para estimar la depreciación, siendo el más conocido el Lineal el cual se aplicará en el caso de las maquinarias adheridas al inmueble (Resolución 620 de 2008 del IGAC, art. 3, p. 2).

\section{Método (técnica) residual}

La Resolución 620 de 2008 del Instituto Geográfico Agustín Codazzi en el artículo 4 al respecto del método de (técnica) residual expresa:

Es el que busca establecer el valor comercial del bien, normalmente para el terreno, a partir de estimar el monto total de las ventas de un proyecto de construcción, acorde con la reglamentación urbanística vigente y de conformidad con el mercado del bien final vendible, en el terreno objeto de avalúo.

Para encontrar el valor total del terreno se debe descontar al monto total de las ventas proyectadas, los costos totales y la utilidad esperada del proyecto constructivo. Es indispensable que además de la factibilidad técnica y jurídica se evalúe la factibilidad comercial del proyecto, es decir la real posibilidad de vender lo proyectado.

\section{Pérdida de valor en el tiempo de un activo}

La pérdida de valor de un activo obedece al concepto de depreciación, que de acuerdo con Omeñaca (2010) y los preceptos generalmente aceptados, las tres posibles 
clases de depreciación del inmovilizado están representadas por amortizaciones, deterioro y bajas. Siguiendo a Omeñaca (2010), la amortización registra una depreciación sistemática e irreversible repartida durante la vida útil de los activos amortizables, convirtiéndose de esta manera en el registro contable anual.

De acuerdo con Omeñaca (2010), el deterioro por su parte se considera una depreciación coyuntural y reversible de dichos activos, es decir, la pérdida de valor obedece a las condiciones del mercado, por lo cual si el mercado logra recuperarse se espera que se recupere el valor de activo, por lo tanto, cuando el valor de mercado o valor razonable menos los costos de ventas están por debajo del valor contable o valor en uso, se estará frente a una situación de deterioro o pérdida de valor para registro en el período.

\section{Métodos de amortización de la pérdida de valor}

La aplicación de los métodos de depreciación es de gran importancia al momento de la estimación del valor de un bien ya que tienen un efecto directo y son tenidos en cuenta a la hora de tasar un bien, a continuación se abordan los métodos de valoración generablemente aceptados.

De acuerdo con Callejas (2008), los métodos de amortización tiene por objeto representar la depreciación de los elementos de inmovilizado según su vida útil y valor residual estimado, mediante la estimación periódica de las cantidades por descontar como parte de los costos por la generación de bienes y servicios en una empresa. Dentro de los métodos convencionales se encuentran:

Método Lineal

(Ecuación 10) $A=\frac{V_{a}-\theta V_{a}}{t_{u}}=\frac{V_{a}(1-\theta)}{t_{u}}$

Donde:

$A$ : Cuota de amortización anual

$V_{a}$ : Valor de adquisición

$\theta$ : Tasas residual, definida como política de la empresa $(\theta<1)$

$t_{u}$ : Período de vida útil

Respecto al método de línea recta, es necesario destacar que en Colombia se tiende a estimar sobre el total del valor de adquisición del activo, asumiendo una mayor cuota de amortización y por ende un mayor escudo fiscal, por lo cual la tasa residual se asume con un valor del $0 \%$. 


\section{Método porcentual}

Consiste en asignar una tasa constante de depreciación, proporcional al período de vida útil generalmente aceptado para el tipo de bien dedicado al proceso productivo, se puede estimar, así:

$$
\text { (Ecuación 11) } A=\delta * V_{a}
$$

Donde:

$A$ : Cuota de amortización anual

$\delta$ : Tasa de depreciación anual $(\operatorname{con} \delta<1)$

Va: Valor de adquisición

El valor de la tasa de depreciación anual " $\delta$ ", toma los valores que se presentan a continuación, teniendo en cuenta el número de años de deterioro y obsolescencia.

Tabla 1. Tabla de equivalencia en años y porcentaje

\begin{tabular}{cc}
\hline Vida útil & Tasa \\
\hline 2 años & $50 \%$ \\
5 años & $20 \%$ \\
10 años & $10 \%$ \\
20 años & $5 \%$ \\
50 años & $2 \%$ \\
\hline
\end{tabular}

Fuente: elaboración propia.

Método porcentual sobre base decreciente

Se estima con un porcentaje fijo sobre el saldo del valor por amortizar.

$$
\text { (Ecuación 12) } A_{t}=\delta *\left(V_{a}-\sum_{t=1}^{n} A_{t-1}\right)
$$

Donde:

$A_{t}$ : Cuota de amortización para cada período $\mathrm{t}$

$\delta$ : Tasa de depreciación anual fija $(\operatorname{con} \delta<1)$

$V a$ : Valor de adquisición

$n$ : Vida útil del bien

$t-1$ : Período anterior de operaciones

\section{Método de suma de dígitos}

De acuerdo con Callejas (2008), el método de suma de dígitos parte del supuesto de que los bienes se deprecian de forma diferente a lo largo de su vida útil, su aplicación 
se puede realizar a través de dos metodologías, el de suma de dígitos decrecientes y suma de dígitos crecientes.

El método de suma de dígitos decrecientes se estima asumiendo un mayor valor de pérdida en los primeros años, por lo que las amortizaciones serán mayores los primeros años y se irán reduciéndose hasta agotar la vida útil del bien, su fórmula de estimación está dada mediante la siguiente ecuación.

Donde:

$$
\text { (Ecuación 13) } A_{t}=\frac{V a(1-\theta)}{\sum_{t=1}^{n} t} *(n-t+1)
$$

$A_{t}$ : Cuota de amortización anual en el año $\mathrm{t}$

$V_{a}$ : Valor de adquisición del activo

$\theta$ : Tasas residual, definida como política de la empresa $(\theta<1)$

$n$ : Número de años de vida útil del activo

$t$ : Año de la amortización

El método de suma de dígitos crecientes, por su parte, asume que el bien se deprecia menos al principio de su vida útil, por lo cual, su amortización aumentara somáticamente hasta agotar la vida útil del bien, su estimación se puede representar mediante la siguiente fórmula:

Donde:

$$
\text { (Ecuación 14) } A_{t}=\frac{V_{a}(1-\theta)}{\sum_{t=1}^{n} t} * t
$$

$A_{t}$ : Cuota de amortización anual en el año $\mathrm{t}$

$V_{a}$ : Valor de adquisición del activo

$\theta$ : Tasa residual, definida como política de la empresa $(\theta<1)$

$n$ : Número de años de vida útil del activo

$t$ : Año de la amortización

\section{Método basado en la actividad}

Siguiendo a Callejas (2008), este método se fundamenta en la estimación del uso o de la productividad del bien, por lo cual la vida útil del bien está en función del número de unidades que producir $\mathrm{u}$ horas de trabajo dedicadas al proceso productivo, por lo cual su fórmula de estimación se estructura como se indica a continuación. 
Donde:

$$
\text { (Ecuación 15) } A_{t}=\frac{\left(V_{a}(1-\theta)\right) *\left(q_{t}\right)}{q^{*}}
$$

$A_{t}$ : Cuota de amortización anual en el año $\mathrm{t}$

$V_{a}$ : Valor de adquisición del activo

$\theta$ : Tasa residual, definida como política de la empresa $(\theta<1)$

$t$ : Año de la amortización

$q^{*}$ : Producción total estimada durante la vida útil del activo

\section{La NIC 36 frente a la determinación del valor de los activos}

La Norma Internacional de Contabilidad (NIC 36) pretende que las empresas al final del período sobre el que se informa, presenten información sobre el valor de sus activos en los estados financieros, en una cifra que no sea superior al importe de recuperación. Entendido este importe, como el mayor entre el valor razonable menos los costos de venta y el valor en uso, pues en caso de superarlos se presenta un deterioro, dando lugar a un registro en los resultados del período. Por lo cual la norma exige que al final de cada período contable en la empresa se apliquen mecanismos para identificar si los activos, el fondo de comercio o los intangibles hayan sufrido una pérdida de valor que amerite ser registrada.

La norma indica que al final del período contable las empresas deben evaluar un potencial deterioro de los activos, aplicando un test de fuentes internas o externas. Sin embargo, en cualquier momento cuando se presente de manera evidente una gran diferencia entre el valor contable del activo y el importe recuperable, se debe registrar el deterioro. De acuerdo con Jónsdóttir (2012) varias empresas realizan los análisis de los fondos de comercio en períodos intermedios del año. Sin embargo, en tiempos de volatilidad e incertidumbre puede requerirse realizar nuevamente el estudio al final del período por la variación de las circunstancias, lo que conllevaría incremento de costos adicionales para las entidades.

Siguiendo a Jónsdóttir (2012) quien plantea que uno de los indicadores externos que son fuente fidedigna para el análisis, es cuando el valor patrimonial de la empresa excede de su valor de capitalización bursátil. Si el valor de la empresa en bolsa es inferior al valor contable, sugiere que el negocio está sobrevalorado, lo cual puede enviar una señal negativa a los inversionistas, quienes no solo miran los rendimientos que recibirán, sino factores relacionados con el desenvolvimiento operativo como cumplimiento de sus acreencias, y continuidad en la operación. En este caso, el valor de una capitalización bursátil inferior al valor contable de la empresa conlleva obligatoriamente al registro de un deterioro afectando los resultados del período. 


\section{Estimación del importe recuperable}

El valor razonable menos los costos de venta es el que se podría obtener en un acuerdo entre partes interesadas, dispuestas a tranzar un valor por el activo, o sea, a partir de un pre-acuerdo de venta, o el precio que se registra acudiendo a un mercado activo, o tomando la mejor información sobre el precio que se podría obtener a través de una venta con un tercero independiente, o tomando registros de transacciones similares en el entorno del activo. La NIC 36 reconoce las dificultades que puede presentar la obtención del valor razonable dando la opción de determinarlo a través del valor en uso.

El valor en uso refleja el valor presente de los flujos de caja futuros que la entidad espera obtener a través del uso del activo y el valor residual si la entidad planea su venta al finalizar su vida útil. Estos flujos deberán descontarse a una tasa que refleje el comportamiento del mercado y el valor temporal del dinero en el tiempo y los riesgos inherentes al activo o la UGE. La norma establece unos parámetros para definir la tasa de descuento para utilizar; Jónsdóttir (2013) considera la WACC (Weighted Average Costo of Capital) como apropiada. Sin embargo, se debe tener especial cuidado en la determinación de la tasa, ya que diferencias insignificantes pueden variar significativamente el valor final de uso, téngase en cuenta que se pueden afectar los resultados del período. Lo que exige mesura en el cálculo de la tasa y poder justificarla ante terceros. Otra tasa puede ser el costo de la deuda para aquellas empresas que tienen deuda cotizada, la cual se puede tomar directamente del mercado. Una tercera, la tasa de interés de los bonos gubernamentales con períodos de redención similares a la vida útil del activo. Una última, puede ser el DTF $+\mathrm{X}$ puntos que es la tasa para determinados sectores, teniendo en cuenta lo que expresa la NIC 36 sobre el reflejo del comportamiento del mercado.

\section{Proceso metodológico}

En el desarrollo del estudio se busca de manera específica las propiedades, características y perfilación en la aplicación de la NIC 36 a los activos utilizados en operaciones de subasta ganadera, a partir de la conceptualización y las variables asociadas para la valoración de activos mediante la utilización del método Montecarlo y la herramienta Excel, tomando como referente un caso de estudio específico de una empresa ganadera.

\section{Activos por valorar y el método}

En el siguiente aparte se definen los procedimientos de estimación para la valoración parcial de los terrenos y corrales que integran un centro de feria ganadera como unidad generadora de efectivo, a partir de la intermediación en los procesos de oferta y demanda ganadera. Igualmente se definen unos principios que fundamentan el método de valoración (Apéndice A). 
Para el proceso de estimación se parte del método de rentas actualizadas proporcionales a la participación relativa del activo a valorar, esto es, se aplica prorrateo en los activos totales respecto a los flujos de caja generados, estableciendo un rango de valor para las simulaciones utilizando un número determinado de escenarios a partir del método Montecarlo, para lo cual se propone la siguiente fórmula:

Donde:

(Ecuación 16) $\operatorname{Min}\left(\sum_{j=1}^{n} \frac{w^{*} f c_{j}}{(1+i)^{n}}\right) \leq v_{m} \leq \operatorname{Max}\left(\sum_{j=1}^{n} \frac{w^{*} f c_{j}}{(1+i)^{n}}\right)$

$V_{m}:$ Valor de mercado estimado en intervalos

$f C_{j}$ : Flujo de caja para cada período j, para m número de simulaciones,

$w$ : Participación relativa del activo sobre el flujo de caja total de la unidad de negocio, resultante como la participación del valor activo entre los activos totales o conjunto.

$i$ : Tasa de oportunidad esperada (PFBCOL benchmark del mercado de referencia)

$n$ : Número total de períodos proyectados

\section{Descripción del método Montecarlo}

Una simulación Montecarlo, de acuerdo con Mun (2005-2012), en su fórmula más simple, es un generador de números aleatorios que es útil para el análisis de pronósticos, estimación y riesgo, a través del cálculo de numerosos contextos o escenarios de un modelo al escoger repetidamente valores de una distribución de probabilidad de un usuario predefinido para las variables inciertas y usando esas variables como insumo para el modelo. Ya que todos los contextos producen resultados asociados en un modelo, donde cada contexto puede tener un pronóstico, los cuales son eventos representados a través de fórmulas o funciones que son definidas como salidas importantes del modelo.

Siguiendo a Mun (2005-2012), los pronósticos usualmente están representados por eventos, tales como ganancias netas o gastos brutos, en este orden de ideas los flujos de caja al ser definidos de forma simulada estarán sometidos a los supuestos de distribución de las variables implícitas que permiten su estimación, esto es los ingresos, y las variables predeterminadas dadas las condiciones propias de operación, tales como costos y gastos de operación e impuestos y la tasa de oportunidad prefijada a partir del costo del patrimonio (CAPM), partiendo de la fórmula básica de estimación a aplicar en el método de simulación, se tiene que:

$$
\text { (Ecuación 17) } \sim f c_{j}=\sim\left(I n_{j}-E g_{j}\right)+A_{j}
$$

$\sim f c_{j}$ : Flujo de caja sujeto al supuesto de distribución de la variable aleatoria, en cada período $\mathrm{j}$ en $\mathrm{n}$ simulaciones 
$I n_{j}$ : Ingresos aleatorios para cada período $\mathrm{j}$ para cada $\mathrm{m}$ simulaciones

$E g_{j}$ : Egresos para cada período j cada m simulaciones

$A_{j}$ : Depreciación estimada para el activo, la cual será fija para cada $\mathrm{m}$ simulaciones

\section{Flujos futuros para determinar el valor de uso}

Los ingresos utilizados como insumo para la determinación del valor de uso, por medio de la simulación y la determinación del VAN, corresponden al promedio del volumen de transacciones de subasta efectuadas en el 2014 por la compañía ganadera de Puerto López, cuyo 3\% equivale a los ingresos, en este escenario donde se realizan eventos de subasta ganadera participan activos que forman parte de la Unidad Generadora de Efectivo (UGE). Siendo el modelo en Excel flexible y adaptable se proyectó en un horizonte de 10 años con un incremento anual de los ingresos del 5\%, y definiendo unos porcentajes de costos y gastos. Los flujos futuros pueden ser descontados entre diferentes opciones pudiendo ser el WACC, el CAPM o tasas del mercado, escogiendo entre estas últimas la tasa de rendimiento de la acción preferencial de Bancolombia PFRBC por ser un referente de volumen de transacciones en el Mercado de Valores de Colombia (Apéndice B).

De acuerdo con Ross, Westerfield y Jaffe (2012) el VAN es una técnica básica cuantitativa para la toma de decisiones financieras, en la que la fórmula para determinar el indicador se asemeja a la siguiente:

(Ecuación 18) $V A N=\sum_{t=1}^{n} \frac{F c j_{1}}{(1+i)}+\frac{F c j_{2}}{(1+i)^{2}}+\frac{F c j_{3}}{(1+i)^{3}}+\cdots+\frac{F c j_{n}}{(1+i)^{n}}$

Sintetizando la fórmula se obtiene:

$$
\text { (Ecuación 18 } \left.{ }^{\mathrm{a}}\right) V A N=\sum_{t=1}^{n} \frac{F c j_{t}}{(1+i)^{t}}
$$

Dónde:

$V A N$ : Valor actual de los flujos futuros

Fcj: Flujo de caja respecto a cada período $\mathrm{t}$

$i$ : Tasa de descuento de los flujos de caja netos

$t$ : Número de períodos de la operación

Para la definición del ingreso se parte de las condiciones propias de operación del negocio, que para el caso de las ferias y subastas ganaderas operan un determinado número de veces al año y una comisión fija sobre el volumen de operaciones que 
se desarrollen valoradas al precio transado, en este orden de ideas, finalmente, la variable sujeta a distribución, estará representada por el monto de las transacciones realizadas en cada evento. De acuerdo con lo anterior el ingreso aleatorio estimado estaría dado por:

$$
\left(\text { Ecuación 19) } \sim \operatorname{In}_{j}=\sum_{i=1}^{n} C *\left(\sim V_{O_{i}}\right)\right.
$$

$\sim I n_{j}$ : Ingreso aleatorio obtenido para cada período $\mathrm{j}$

$C$ : comisión fija para cada operación (fijada en un 3\%)

$i$ : Número de operaciones analizadas

$n$ : Total de operaciones realizadas

$*\left(\sim V_{O_{i}}\right)$ : Volumen en términos monetarios resultante de cada operación de compra y venta de ganado, sujeto a los supuestos de distribución determinados por el estadístico Kolmogorov-Smirnov.

Esta última fórmula de estimación comporte la variable aleatoria independiente, movida por la ley de la oferta y la demanda, representada por el volumen de operaciones en términos monetarios para cada subasta realizada, que dinamiza el proceso de análisis del comportamiento de los flujos de caja.

La aplicación del estadístico Kolmogorov-Smirnov permite contrastar el comportamiento empírico respecto al teórico de una variable, definiendo de acuerdo con una tendencia el tipo de probabilidad que le corresponde a la variable entre un total de 33 tipos de distribuciones, sometidas a análisis a través en un software especializado para su aplicación, para efectos de este análisis se ha tenido en cuenta el software Risk Simulator versión 2013, estructurando a través de una hoja de cálculo organizada la información de forma sistemática, para obtener el número de escenarios prefijados y de esta manera someterlas al análisis definitivo de los resultados (Apéndice $\mathrm{C}$ ).

Respecto a los resultados obtenidos se espera determinar, dadas los condiciones de operación, un rango de datos que ubique el posible valor razonable en el rango estimado de datos y definir dados los valores mínimos y máximos establecidos la posibilidad de deterioro que podría sufrir el activo o conjunto de activos analizados, dado su valor en libros en el período de inicio de la estimación.

Por lo cual se plantea como hipótesis de resultado que:

El valor en libros del activo en la fecha de estudio, se encuentra dentro del rango estimado a partir de la simulación con los ingresos futuros, garantizándose así la no causación de deterioro de los activos valorados. 


\section{Valoración de los terrenos y corrales}

Para el proceso de estimación se han seleccionado como activo de forma conjunta los terrenos y corrales, partiendo del porcentaje de participación estimada en los activos totales a partir de la estructura de activos que integra una feria y subastas como unidad generadora de efectivo de forma conjunta y definiendo unos insumos para la valoración (Apéndice D)

\section{Supuestos de valoración}

En el proceso metodológico de estimación de la valoración de los terrenos y corrales se contemplan los siguientes supuestos de estimación.

Los activos de la unidad generadora de efectivo presentan las siguientes estructuras de participación, descritas en la tabla 2.

Tabla 2. Participación en la estructura de inversión

\begin{tabular}{lcc}
\hline Efectivo & 10.000 .000 & $1 \%$ \\
Terrenos $^{\mathrm{a}}$ & 750.000 .000 & $48 \%$ \\
Corrales & 250.000 .000 & $16 \%$ \\
Básculas & 120.000 .000 & $8 \%$ \\
Pantallas lcd & 65.000 .000 & $4 \%$ \\
Jaula & 60.000 .000 & $4 \%$ \\
Computador & 20.000 .000 & $1 \%$ \\
Escenario & 250.000 .000 & $16 \%$ \\
Otros activos & 30.000 .000 & $2 \%$ \\
\hline Total & 1.555 .000 .000 & $100 \%$ \\
\hline
\end{tabular}

Fuente: elaboración propia.

Nota: a. Los terrenos están representados por $5000 \mathrm{~m}^{2}$ con un valor de mercado estimado para la zona de $\$ 150.000 \mathrm{~m}^{2}$ de acuerdo con entrevista realizada al perito miembro avaluador de la Lonja de Propiedad Raíz de Los Llanos.

El cuadro implica que los activos a valorar tienen un peso del 64\% sobre los flujos de caja, representados en un $48 \%$ por la participación de los terrenos y $16 \%$ en corrales, respectivamente.

Los corrales se deprecian bajo el método de línea recta, amortizaciones anuales de $\$ 25.000 .000$

La variable aleatoria está representada por los ingresos por ventas de especímenes machos y hembras, el cual está sujeto a la ley de la oferta y la demanda generada en los espacios de ferias semanales. 
Esta variable comporta una distribución logarítmica normal (Apéndice B), cuyos parámetros están representados por la media y la desviación, los cuales se ilustran a continuación, mediante la tabla 3.

Tabla 3. Comportamiento de media y desviación

\begin{tabular}{lrr}
\hline \multicolumn{1}{c}{ Estadísticos } & \multicolumn{1}{l}{ Real } & \multicolumn{1}{l}{ Teórica } \\
\hline Media & $424.042 .962,17$ & $426.250 .151,15$ \\
Desviación Estándar & $127.179 .409,76$ & $127.841 .390,78$ \\
Asimetría & 0,46 & 0,93 \\
Curtósis & $-0,04$ & 1,57 \\
\hline
\end{tabular}

Fuente: elaboración propia.

Los porcentajes de comisión de los ingresos son del 3\% del valor de subastas semanales. Los ingresos se incrementan a una tasa anual del 5\%. Los costos representan un $25 \%$ de los ingresos obtenidos y el margen de gastos un 30\%. La tasa de impuesto está representada en un 39\% sobre las utilidades antes de impuestos, correspondientes a una tasa de renta del $25 \%$, un $9 \%$ de impuesto de renta a la equidad y una sobretasa del $5 \%$.

La tasa de oportunidad está representada por la rentabilidad anualizada de la acción más rentable del mercado de valores de Colombia del período anterior, representada por la acción preferencial de Bancolombia, con un retorno del 24,68\% efectivo anual (Apéndice D).

El valor de los activos de mercado con un 95\% de confianza, estará dado por un rango aleatorio resultante de una simulación de 5000 escenarios, entre un valor mínimo y máximo en el cual los interesados deben concertar.

El costo de la transacción incluido el proceso de valoración será del 10\% del valor de mercado definido. El valor razonable estará dado por la diferencia de los valores externos y el costo de estimación, establecido. Los conceptos están definidos en el (Apéndice E).

Para el cumplimiento de la hipótesis se espera que el valor en libros de los activos en la fecha de estudio no esté por encima del máximo valor del rango que define el valor de uso según Montecarlo o del VPN según cálculo en Excel, para no registrar deterioro.

\section{Estimación del valor de las unidades generadoras de efectivo bajo el método Montecarlo}

Aplicados los condicionamientos de los supuestos y al aplicar la simulación de escenarios en el software Risk Simulator se obtiene los resultados que se muestran a continuación: 
Figura 1. Valor esperado de las unidades generadoras de efectivo

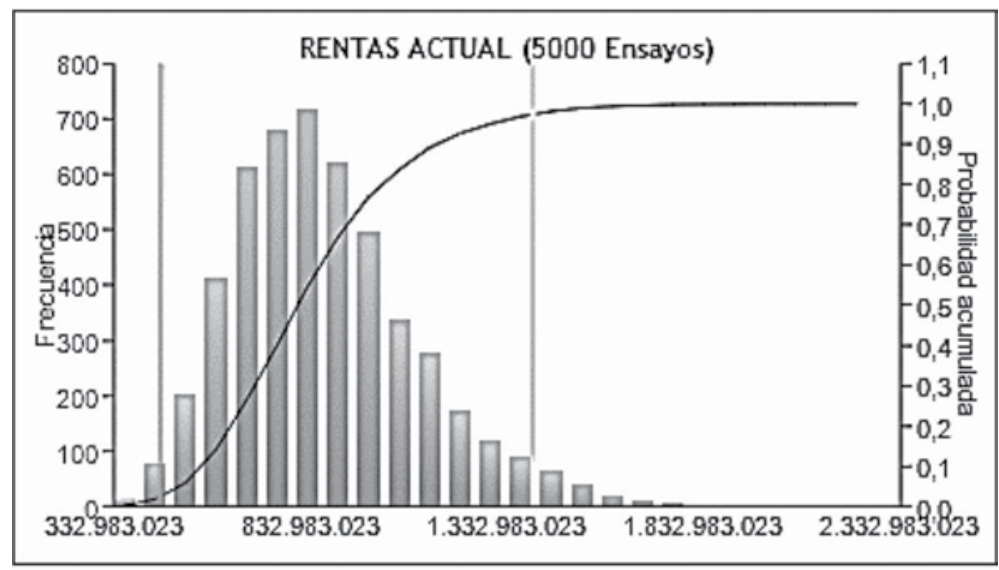

Tipo: Doble vínculo, Más Bajo: 451.614.973, Superior: 1.398.295.630, Certeza: $95,0000 \%$

Fuente: elaborado con estimaciones propias del investigador y mediante el Software Risk Simulator.

De acuerdo con los resultados de la simulación, se observa que el valor de negociación o flujos futuros de los activos estará entre un mínimo $\$ 451.614 .973$ moneda corriente a 2015 y un valor máximo de $\$ 1.398 .295 .630$ con un $95 \%$ de confianza bajo los parámetros de análisis de doble vínculo de la aplicación del método de simulación Montecarlo en el software Risk Simulator.

\section{Cálculo del VNA con Excel}

Los supuestos de estimación para el análisis de escenario, respecto a los ingresos, estos parten del promedio de los valores transados en la subasta durante el 2014 (\$725.250.056) sobre el cual las empresas de subasta ganadera reciben comisión del $3 \%$ sobre la actividad operando 52 semanas del año, el cual arroja una cifra para el año 0 de $\$ 1.131 .390 .087$, los costos se estimaron en un $25 \%$ y los gastos en un $30 \%$, los impuestos en 39\%, y tasa de descuento del 24,68\% a partir de la acción más liquida y rentable de la Bolsa de Valores de Colombia del año en estudio (PFBCOL) y un porcentaje de participación de activos del 64\%, lo cual permite obtener un VAN de los flujos futuros de \$1.394.691.012 (Apéndice B).

\section{Conclusiones y recomendaciones}

De acuerdo con los resultados de la simulación según Montecarlo, se puede observar que el valor en libros de los activos (terrenos y corrales) representado en la suma de \$1.000.000.000 se encuentra dentro del rango de valor obtenido de los flujos futuros en un horizonte de 10 años, al presentar un mínimo de $\$ 451.614 .973$ y valor 
máximo de $\$ 1.398 .295 .630$ con un $95 \%$ de confianza bajo los parámetros de análisis de doble vínculo; lo cual cumple con el precepto señalado en el numeral 20 de la NIC 36 que dice:

No siempre es necesario calcular el valor razonable del activo menos los costos y su valor de uso. Si cualquiera de esos importes excediera al importe en libros del activo, este no habría sufrido un deterioro de su valor, y por tanto no sería necesario calcular el otro valor. En el caso que nos ocupa no hay lugar a registrar deterioro.

De otro lado, haciendo la proyección en Excel para determinar un VNA de los flujos futuros con los ingresos de subasta bajo los mismos supuestos descritos, nos arroja un resultado VNA de $\$ 1.394 .691 .012$, los cuales al ser contrastados con el valor en libros de los activos por $\$ 1.000 .000 .000$, no dan lugar a registrar deterioro.

De lo anterior se infiere el cumplimiento de la hipótesis planteada, de un valor en libros de los activos por debajo del valor máximo del rango estimado, a partir de la simulación que identifica el valor de uso para no causar el registro de deterioro. Igualmente, la cifra arrojada por el cálculo del VAN en Excel, corrobora dicha afirmación, en el sentido de que el valor en libros se sitúa por debajo del valor en uso de acuerdo con el cumplimiento de los pronósticos de ingresos, que son determinantes en los flujos de cajas esperados.

\section{Referencias}

Bunge, M. (1985). Economía y filosofía. Madrid, España: Editorial Tecnos S.A.

Callejas, J. (2008). Concepto de amortización elementos de inmovilizado. Departamento de Publicaciones del IE María de Molina 13. 28006 - Madrid, España. Recuperado de http://recursos.salonesvirtuales.com/assets/bloques// Joseluis_Calleja.pdf

Gallego, E. (2008). Modelos de valoración automatizada. CT: Catastro, (65), 7-26.

García, N. (2004). Desarrollo de aplicaciones de redes neuronales artificiales al mercado inmobiliario: aplicación a la ciudad de Albacete. (Tesis doctoral).

González, P., Turmo de Padura, J. y Villalonga, E. (2006). La valoración inmobiliaria: Teoría y práctica. Madrid, España: La Ley.

Griliches, Z. (1971). Introduction: Hedonic Price index Revisited. In Price Indexes and Quality Changes: Studies in New Methods of Measurement (pp. 3-15). Cambrige: Harvard University Press.

Jara, L., Torres, L., y Contreras, H. (2009, enero-marzo). Modelación NIC 36 en sociedades anónimas abiertas con baja presencia bursátil. Revista Internacional Legis de Contabilidad y Auditoría, 11-44. 
Jónsdóttir, H. (2012). Resumen Ejecutivo. Deterioro Aplicación Práctica de la NIC 36 (I). Ernst \& Young.

Jónsdóttir, H. (2013). Resumen Ejecutivo. Deterioro Aplicación Práctica de la NIC 36 (II). Ernst \& Young.

Kauko, T. (2009). The Housing Market Dynamics of Two Budapest Neighbourhoods. Housing Studies, 24(5), 587-610.

Kontrina, V., y Verikas, A. (2011). The mass appraisal of the real estate by computational intelligence. Applied Soft Computing, 11(1), 443-448.

KPMG Consultora. (2014). Folleto activo tangible. Recuperado de https://www.kpmg. com/MX/es/IssuesAndInsights/ArticlesPublications/Documents/Folletos/2014/ Folleto-Activos-Tangibles.pdf

Mun, J. (2005-2012). Simulador de riesgo. Manual de usuario en español. California, Estados Unidos: Real Options Valuation.

Norma Internacional de Contabilidad (NIC) 36. Deterioro del valor de los activos. Recuperado de http:/www.normasinternacionalesdecontabilidad.es/nic/pdf/ NIC36.pdf

Omeñaca, J. (2010). Amortización y deterioro de los inmuebles en la coyuntura de la burbuja inmobiliaria. Partida Doble, (222), 38-48.

Pagourtzi, E., Assimakopoulos, V., Hatzichristos, T., y French, N. (2003). Real estate appraisal: a review of valuation methods. Journal of Property Investment \& Finance, 21(4), 383-401.

Perea, S. (2014). Deterioro del valor de los activos a la luz de la teoría del valor. Revista Lúmina, (15), 130-145.

Resolución 620 de 2008 de la Dirección General del Instituto Geográfico Agustín Codazzi. (23 de septiembre de 2008). Por la cual se establecen los procedimientos para los avalúos ordenados dentro del marco de la Ley 388 de 1997. Recuperado de http://www2.igac.gov.co/igac_web/normograma_files/RESOLUCION\%20 $620+\mathrm{DE}+2008 . \mathrm{pdf}$

Rey, J. (2014). Alternativas y determinantes en valoración de inmuebles urbanos (Tesis doctoral). Universidad de Córdoba, Córdoba, España.

Ross, S., Westerfield, R., y Jaffe, J. (2012). Finanzas corporativas. México D.F.: McGraw Hill. Recuperado de https://rosirismendoza.files.wordpress. com/2014/04/libro-finanzasross.pdf

Rosen, S. (1974). Hedonic Pirces and Implicit Markets: Product Diferentiation in Pure Competition. Journal of Polical Economy, 34 -55. 
Selim, H. (2009). Determinants of house prices in Turkey: Hedonic regression versus artificial neural network. Expert Systems with Applications, 36.

Tse, R. (1997). An aplication of the ARIMA model to real-estate prices in Hong Kong. Journal of Property Finance, 8(2), 152-163. Recuperado de http://citeseerx. ist.psu.edu/viewdoc/download?doi=10.1.1.196.4606\&rep $=$ rep1\&type $=$ pdf

VV. AA. (2009). El Arte de Valorar Empresas. Fundación de Estudios Bursátiles y Financieros. Valencia, España: S.L. Civitas Ediciones. 


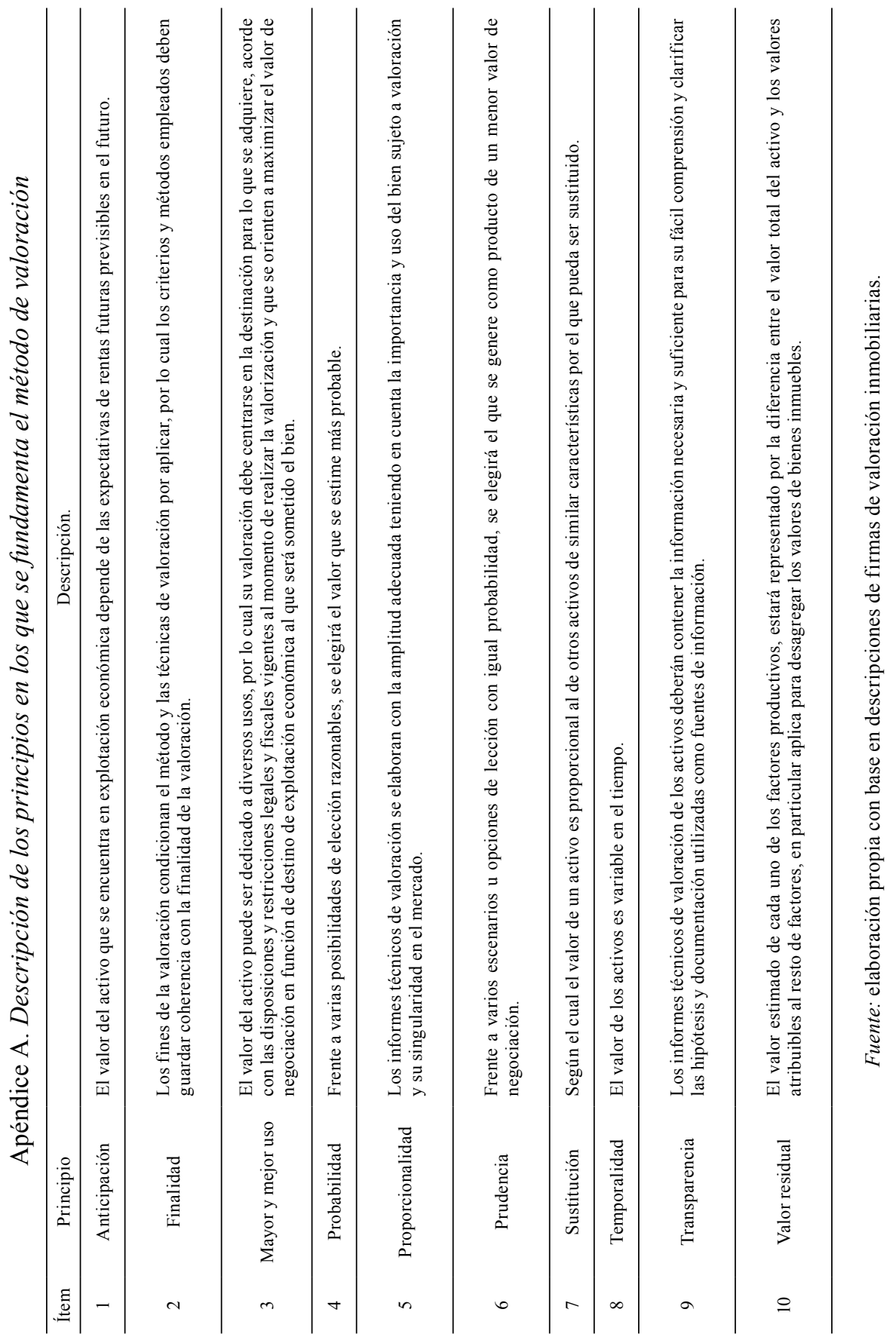




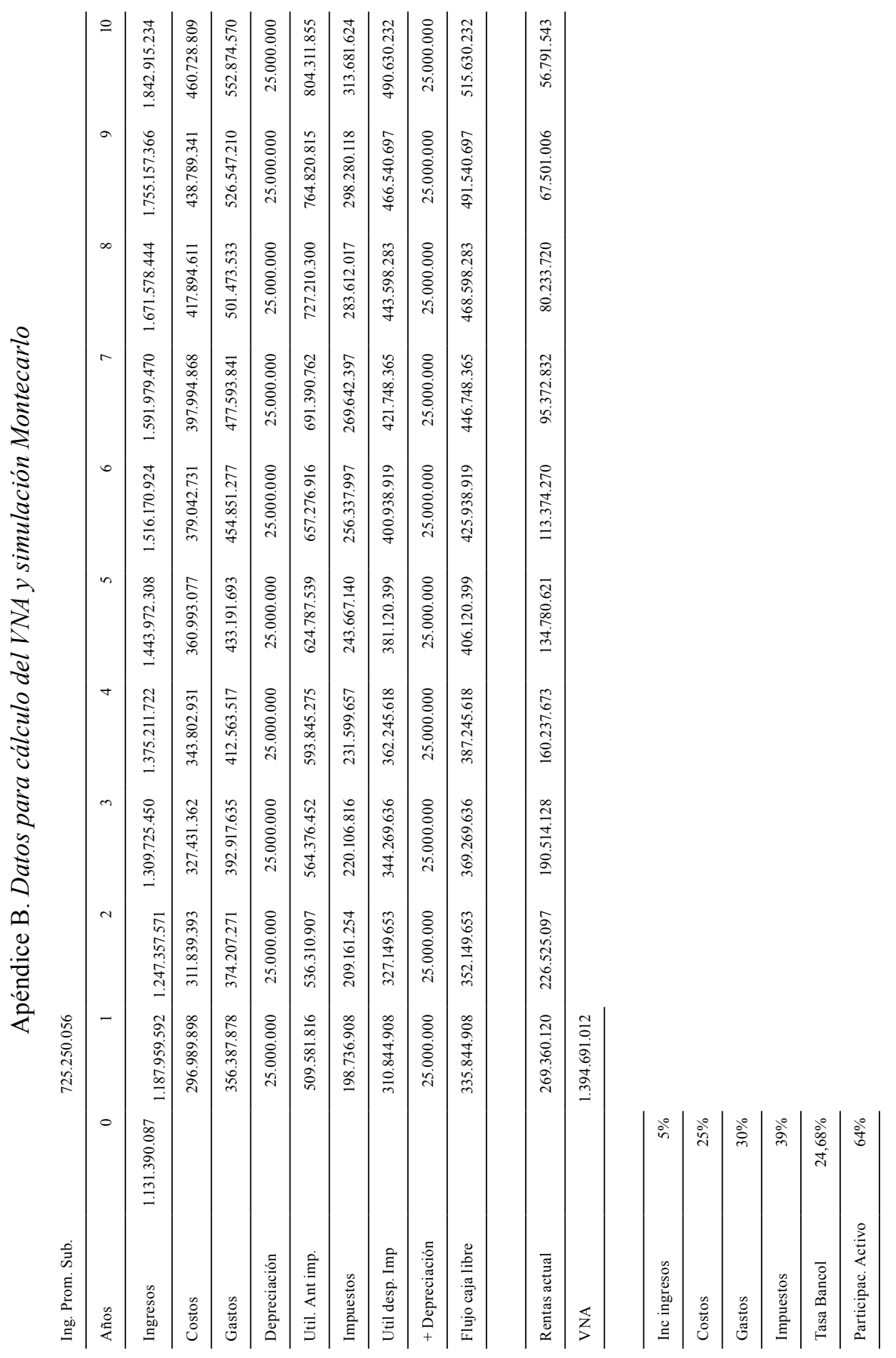


Método de estimación del valor de uso de activos utilizados en operaciones de subastas...
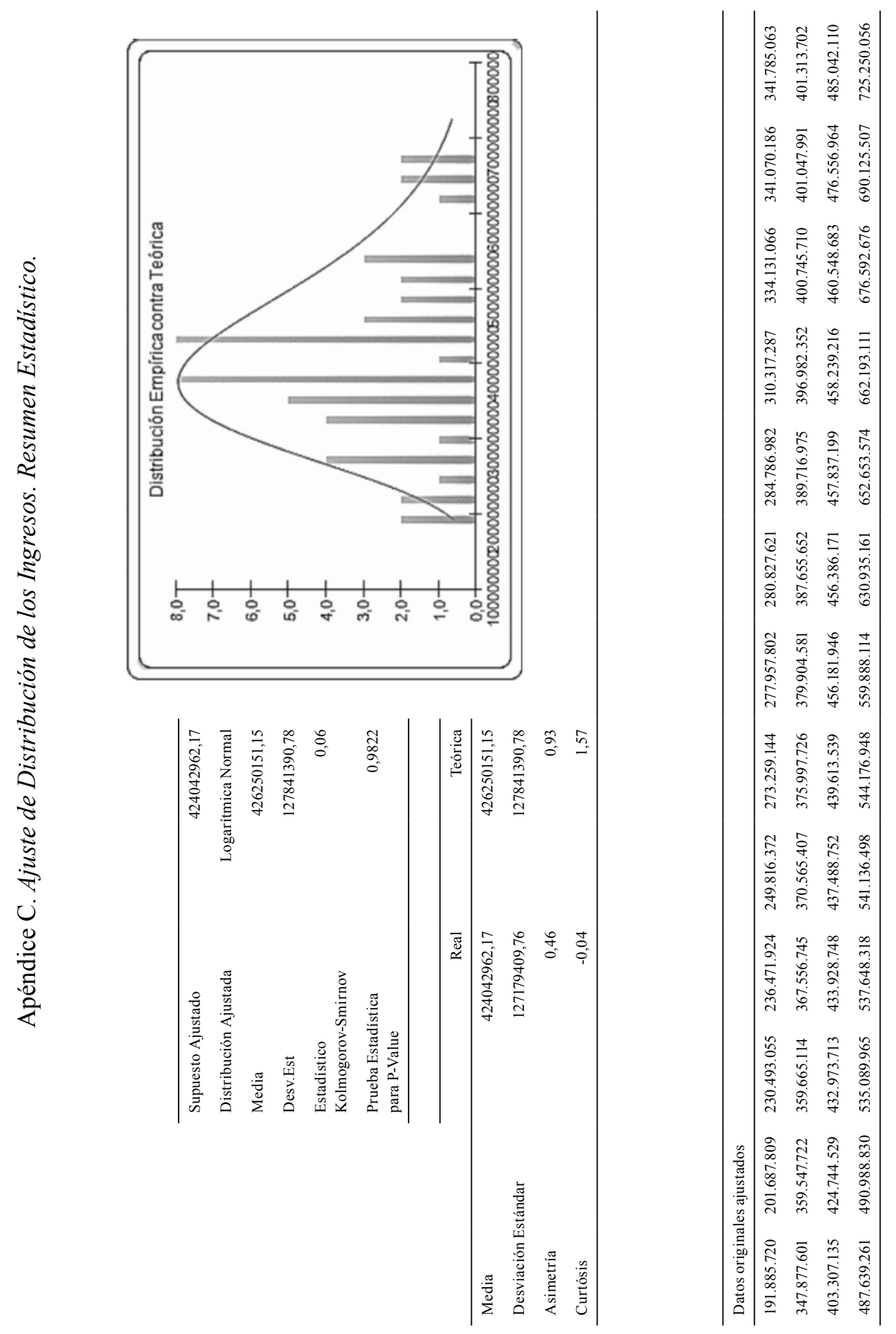


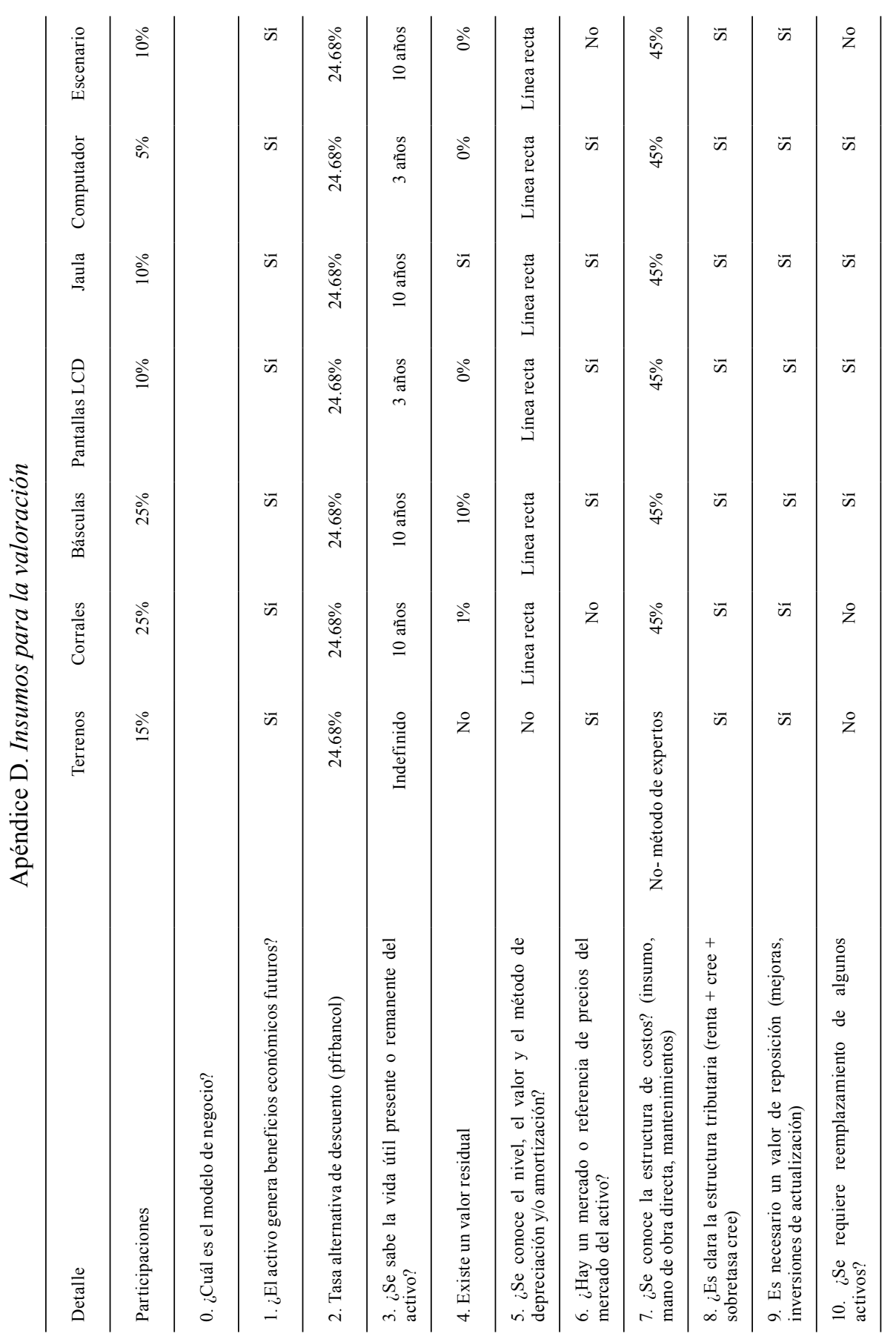




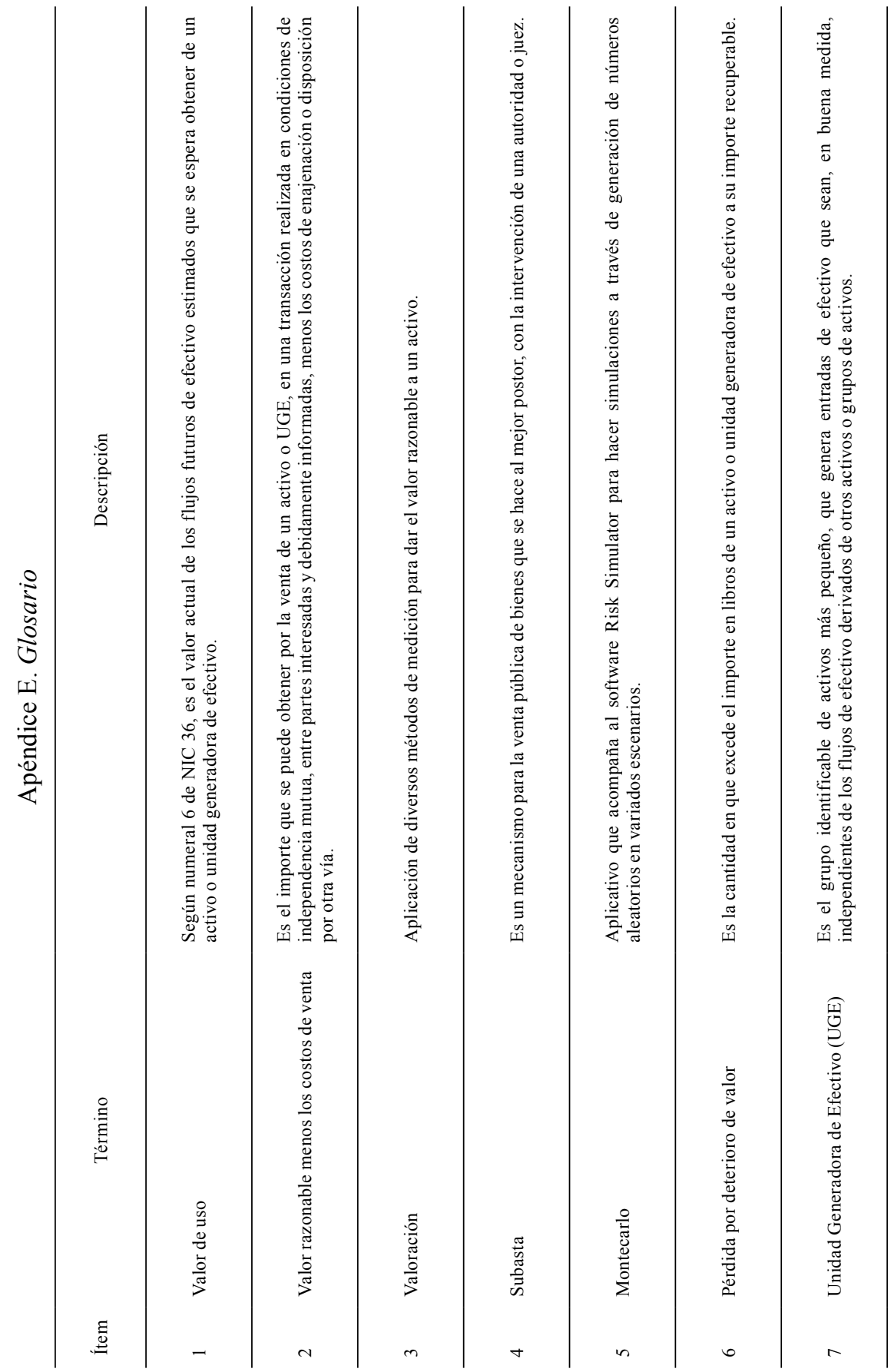

